\title{
Phase Change Material Systems for High Temperature Heat Storage
}

\author{
David Y. S. Perraudin ${ }^{\mathrm{a}}$, Selmar R. Binder ${ }^{\mathrm{a} \$}$, Ehsan Rezaeiab, Alberto Ortona ${ }^{\mathrm{ab}}$, and Sophia \\ Haussener ${ }^{\star a}$
}

\begin{abstract}
Efficient, cost effective, and stable high-temperature heat storage material systems are important in applications such as high-temperature industrial processes (metal processing, cement and glass manufacturing, etc.), or electricity storage using advanced adiabatic compressed air energy storage. Incorporating phase change media into heat storage systems provides an advantage of storing and releasing heat at nearly constant temperature, allowing steady and optimized operation of the downstream processes. The choice of, and compatibility of materials and encapsulation for the phase change section is crucial, as these must guarantee good and stable performance and long lifetime at low cost. Detailed knowledge of the material properties and stability, and the coupled heat transfer, phase change, and fluid flow are required to allow for performance and lifetime predictions. We present coupled experimental-numerical techniques allowing prediction of the long-term performance of a phase change material-based high-temperature heat storage system. The experimental investigations focus on determination of material properties (melting temperature, heat of fusion, etc.) and phase change material and encapsulation interaction (stability, interface reactions, etc.). The computational investigations focus on an understanding of the multi-mode heat transfer, fluid flow, and phase change processes in order to design the material system for enhanced performance. The importance of both the experimental and numerical approaches is highlighted and we give an example of how both approaches can be complementarily used for the investigation of long-term performance.
\end{abstract}

Keywords: High-temperature heat storage - Latent heat of fusion - Multimode heat transfer Phase change materials - Thermal energy storage

\section{Introduction}

The Swiss industrial sector uses about $50 \%$ of its energy for process heat. ${ }^{[1]}$ This process heat is provided by fuels $(74 \%)$ and electricity $(26 \%)$. Based on the European heat market statistics $40 \%{ }^{[2]}$ of that heat is high-temperature heat $\left(>400{ }^{\circ} \mathrm{C}\right)$, thus accounting for an estimated $4.6 \%$ of the total end energy consumption in Switzerland. The metal processing and chemical industries are main consumers. The large exergy content of hightemperature heat, the non-continuous industrial processing routes, and the intermittency of some heat sources are drivers to develop high-temperature heat storage

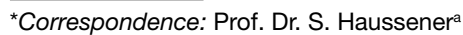
E-mail: sophia.haussener@epfl.ch

aÉcole Polytechnique Fédérale de Lausanne (EPFL) Institute of Mechanical Engineering, LRESE

$\mathrm{CH}-1015$ Lausanne, Switzerland

bScuola universitaria professionale della Svizzera italiana (SUPSI)

Department for Innovative Technologies, ICIMSI

$\mathrm{CH}-6928$ Manno, Switzerland

\$Equally contributing authors systems. Other applications for hightemperature heat storage include concentrated solar power and electricity storage by advanced adiabatic compressed air energy storage (AA-CAES). ${ }^{[3]}$ The latter represents one of the main complementing large-scale electricity storage approaches to pumped hydro electricity storage.

The design of thermal energy storage systems highly depends on the application, which defines its temperature level, energy storage capacity, storage duration, and charge and discharge rates. In addition to the technical and performance requirements, long lifetime, low cost, high volumetric energy density, and stable operation are key factors for a practical heat storage system.

Heat can be stored in the form of sensible and latent heat. Latent heat storage systems often use the solid/liquid phase transition due to volumetric constraints. If a material with a well-defined melting point is used (such as pure elements, compounds, or eutectics) then storing heat by means of a phase change makes it possible to stabilize the temperature at which heat is discharged. The downstream processes can subsequently operate stably and optimally at a specified temperature. As sensible heat storage materials tend to be less costly than phase change materials (PCMs), combined sensible-latent heat storage systems are developed to provide stabilized output temperatures at reduced cost. ${ }^{[4]}$ An additional challenge of PCMs is the requirements of containment in the molten stage. The stability of the interface between the PCM and the encapsulation is crucial for high and stable long-term performance, especially in high-temperature environments. Complex interlayers can ensure the mechanical and chemical stability while maintaining efficient heat transfer.

A generic latent heat storage system is shown in Fig. 1 utilizing a heat transfer fluid (HTF) to provide and evacuate the high-temperature heat. Heat is transferred from the hot HTF to the solid PCM during charging. The PCM undergoes melting and thus absorbs the latent heat of fusion within a narrow temperature range. When discharging, the reverse process occurs. A part of the heat can be stored as sensible heat in the encapsulation and interlayer, and in the PCM if it is completely melted and further heated above the melting temperature. The material combinations used for the heat storage system (PCM, interlayer, encapsulation) must be chosen carefully. The mechanical stability and good heat transfer performance must be ensured while guaranteeing chemical stability and inertness of the interfaces and interlayers. Detailed analysis of the heat transfer, fluid flow and phase change processes is 


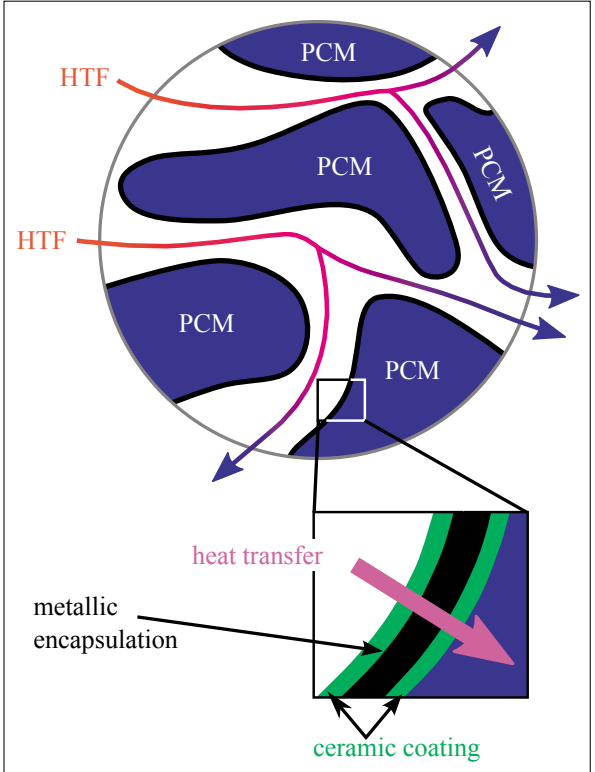

Fig. 1. Generic latent heat thermal energy storage system in its charging state incorporating hot HTF, solid PCM, encapsulation, and stabilizing interlayers.

required to predict and enhance the system performance while investigation of the interactions between the components and at the interfaces are required to predict and enhance the durability, stability, and system lifetime.

\section{Phase Change Materials (PCM)}

Phase change materials are commonly classified as organic or inorganic. [5] Organic materials are rarely stable above $400{ }^{\circ} \mathrm{C}$ making them unworkable for hightemperature heat storage. Among the inorganic materials, salts are often cheaper while metals outperform their counterparts in terms of high thermal conductivity and heat of fusion (see Table 1). Heat transfer enhancement techniques, such as the immersion of metal meshes, have been investigated for salts ${ }^{[5-8]}$ but result in more complex material systems with reduced per volume and mass amount of active PCM material.

The detailed knowledge of material properties, such as melting temperature, heat of fusion, heat capacity, density, thermal conductivity, sub-cooling and thermal expansion coefficient, is of paramount importance when evaluating the performance of phase change materials. Data can be obtained from literature for elements and well known compounds, but are not always readily available or consistent for new PCMs under consideration. Differential scanning calorimetry (DSC), which is typically used to determine phase transformations and associated energies (glass transition temperature, melting temperature, heat of fusion), can be of limited applicability since the properties of bulk PCMs can vary from that of small samples (in the order of $\mathrm{mg}$ ) used in this technique. The T-history method can be employed to investigate the thermo-physical properties (melting temperature, sub-cooling, specific heat capacity and heat of fusion) of different PCMs by melting and solidifying at controlled environment temperatures. ${ }^{[12]}$ This type of measurement provides a fast and nondestructive way to measure bulk properties for encapsulated systems. A set of assumptions on sample geometry (i.e. cylindrical symmetry and aspect ratio) and heat transfer to the environment have to be verified for the results to be reliable. A typical Thistory measurement for $\mathrm{Al}-12 \mathrm{Si}$ is shown in Fig. 2 allowing for the determination of the melting temperature and sub-cooling.

To address the stability of PCM and encapsulation the above-mentioned thermophysical characterization techniques can be employed in sequence with typical load cycles. In addition, post mortem inspection of encapsulated PCM samples can give insight into degradation mechanisms and extent. In the case of steel encapsulated aluminum alloys an intermetallic reaction product forms at the interface and can be quantified visually after cross-sectioning. The formed iron aluminides are brittle and may deteriorate the mechanical properties of the encapsulation. ${ }^{[13,14]}$

Table 1. Thermo-physical properties of selected inorganic PCM. Metal alloy conductivities for the solid and liquid phases, salt conductivities for the solid phase.

\begin{tabular}{lllll} 
Classification & Compound & $\begin{array}{l}\text { Melting } \\
\text { temperature } \\
{\left[{ }^{\circ} \mathrm{C}\right]}\end{array}$ & $\begin{array}{l}\text { Heat of } \\
\text { fusion } \\
{\left[\mathrm{Jg}^{-1}\right]}\end{array}$ & $\begin{array}{l}\text { Thermal } \\
\text { conductivity } \\
{\left[\mathrm{Wm}^{-1} \mathrm{~K}^{-1}\right]}\end{array}$ \\
\hline \multirow{3}{*}{ Metal alloy } & $\mathrm{Al} 12 \mathrm{Si}$ & $575^{[9]}$ & $560^{[9]}$ & $180 / 70^{[10]}$ \\
& $\mathrm{Al} 12 \mathrm{Si} 5 \mathrm{Mg}$ & $560^{[11]}$ & $545^{[11]}$ & $200 / 70^{[11]}$ \\
& $\mathrm{Al} 33 \mathrm{Cu}$ & $548^{[11]}$ & $351^{[11]}$ & $130 / 80^{[11]}$ \\
\multirow{3}{*}{ Salts } & $\mathrm{NaNO}_{3}$ & $306^{[8]}$ & $172^{[8]}$ & $0.6^{[8]}$ \\
& $\mathrm{NaCl}$ & $800^{[8]}$ & $492^{[8]}$ & $5^{[8]}$ \\
\hline & $\mathrm{Na}_{2} \mathrm{CO}_{3}$ & $854^{[8]}$ & $275.7^{[8]}$ & $2^{[8]}$
\end{tabular}

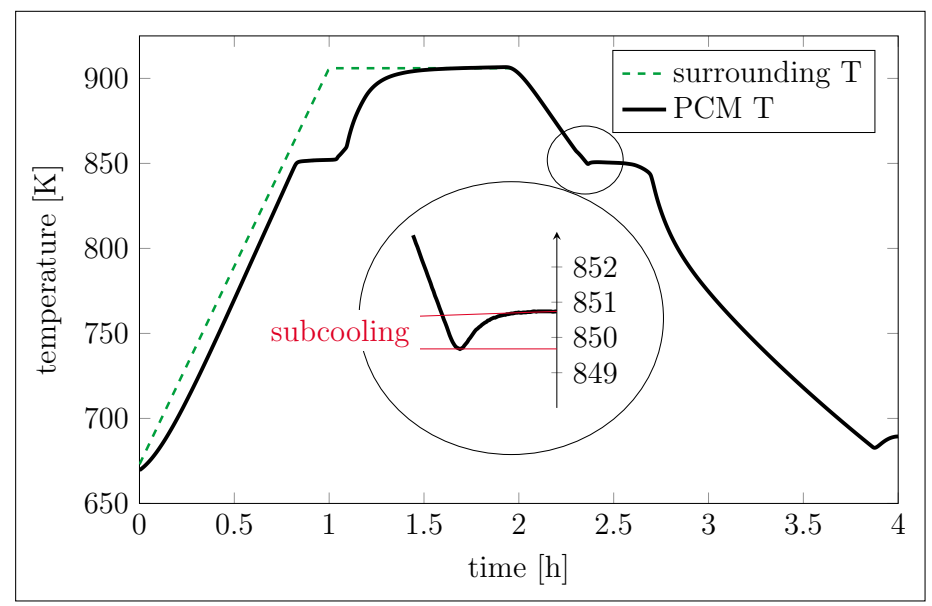

Fig. 2. Temperature measurement for Al-12Si encapsulated in an AISI $316 \mathrm{~L}$ steel tube $(2.13 \mathrm{~cm}$ outer diameter, 2.53 $\mathrm{mm}$ wall thickness). Preset oven temperature ramp during heating (charging) is indicated in green. Oven was turned off during cooling (discharging). 
$27 \mathrm{~g}$ of Al-12Si. This illustrates the need for material system designs that increase the specific surface per unit mass of PCM such as provided by porous structures.

For the comparison of different material system designs, numerical simulations are the tool of choice. The phase change is attributed to the general class of free boundary problem due to the presence of melting or solidification fronts which evolve and represent a discontinuity in material properties. Early attempts of numerical solution are documented by Voller et al. ${ }^{[15]}$ The work of Voller led to the enthalpy porosity-method, ${ }^{[16]}$ the state-ofthe art method for phase change simulations implemented in commercial software (ANSYS, COMSOL). While such simulations allow to better understand the physics of multi-mode heat transfer processes, it has been demonstrated, ${ }^{[17]}$ that the requirement for semi-empirical constants has a significant influence on the solution. Due to their weak relation to first principles, their tuning with reference to experiments is necessary and the predictive power of the method is limited. This underlines the necessity of a dual approach, including simulations and experimental validation.

\section{Chemical Stability and Performance Losses of PCM in AA-CAES Application}

The following illustrates current efforts at our laboratory to develop tailored highperforming and stable high-temperature heat storage material systems. Specifically, we illustrate the effect of chemical degradation on the performance of a heat storage system. For that purpose the chemical stability of an aluminum alloy Al-12Si encapsulated in an AISI 316L steel tube relevant in AA-CAES application - was investigated experimentally and the results were included in a numerical simulation to assess the impact of chemical degradation on the long-term heat storage characteristics.

\subsection{Experimental Data}

For the investigation of chemical stability, 20 AISI $316 \mathrm{~L}$ steel cylinders with $21.3 \mathrm{~mm}$ outer diameter, $6 \mathrm{~cm}$ height, and $2.53 \mathrm{~mm}$ wall thickness were filled with approx. $27 \mathrm{~g}$ of Al-12Si and heated in a furnace to $700{ }^{\circ} \mathrm{C}$. After different time periods the samples were removed from the oven and cooled to ambient. Cross-sectioning revealed, in accordance with literature ${ }^{[18,19]}$ that an iron- and aluminum-rich intermetallic interlayer had formed as the PCM reacted with the encapsulation (confirmed by SEM-EDX). The quantified growth of the intermetallic layer thickness is illustrated in Fig. 3 together with an empirical fit. The growth kinetics of the intermetallic layer is generally accepted to be diffusion controlled ${ }^{18]}$ and monotonic growth over time is expected.[19] Since PCM is consumed to form high melting products $\left(T_{\mathrm{m}}\right.$ $\geq 1160{ }^{\circ} \mathrm{C}^{[13]}$ ) which act as a sensible heat material, the performance is expected to be altered. At the same time the mechanical stability is affected, as the interlayer is hard (up to $1000 \mathrm{HV}^{[14]}$ ) and brittle enough to fracture from thermal stresses upon cooling the sample to ambient conditions.

\subsection{Numerical Simulation}

The impact of interlayer growth on performance was predicted by applying numerical simulations and using the measured interlayer growth thickness. A onedimensional model was applied and the enthalpy method was used. ${ }^{[15]}$ No convection was assumed and changes in density of the aluminum alloy were neglected, such that no empirical constants were required as input to the model. For comparison, the

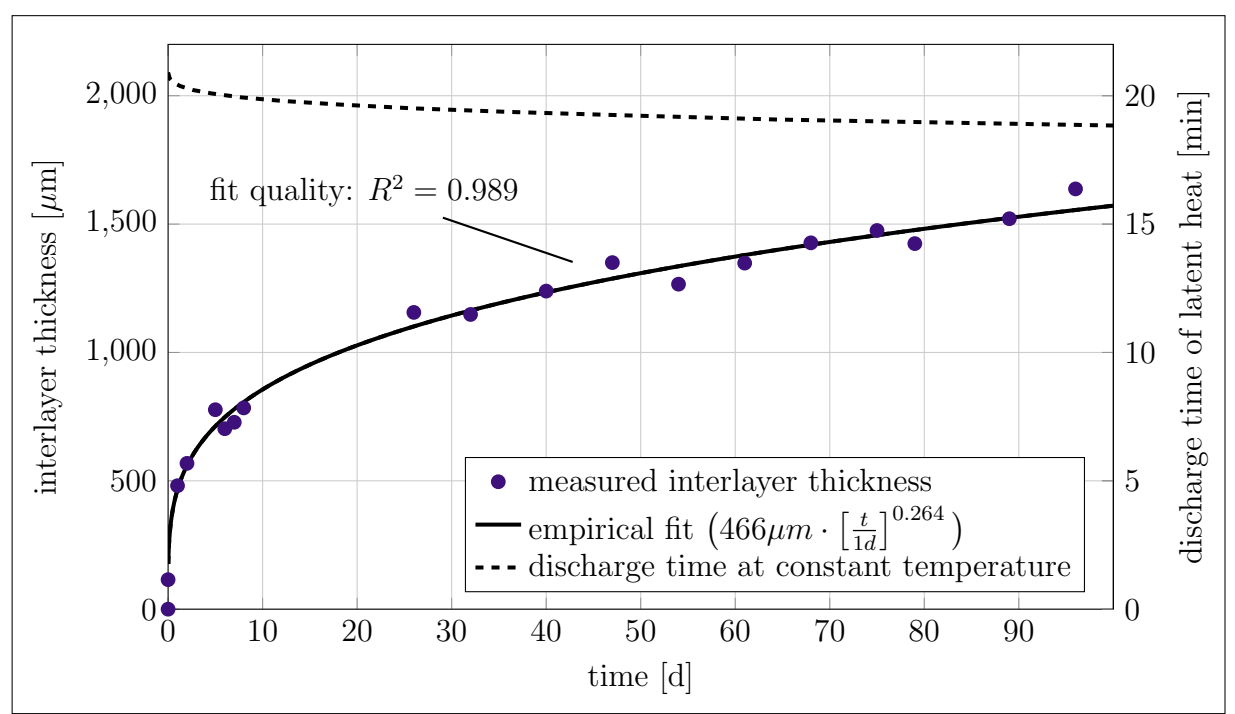

Fig. 3. Measured and fitted intermetallic layer growth for Al-12Si encapsulated in an AISI 316 L steel cylinder and decrease in discharge time at constant temperature.

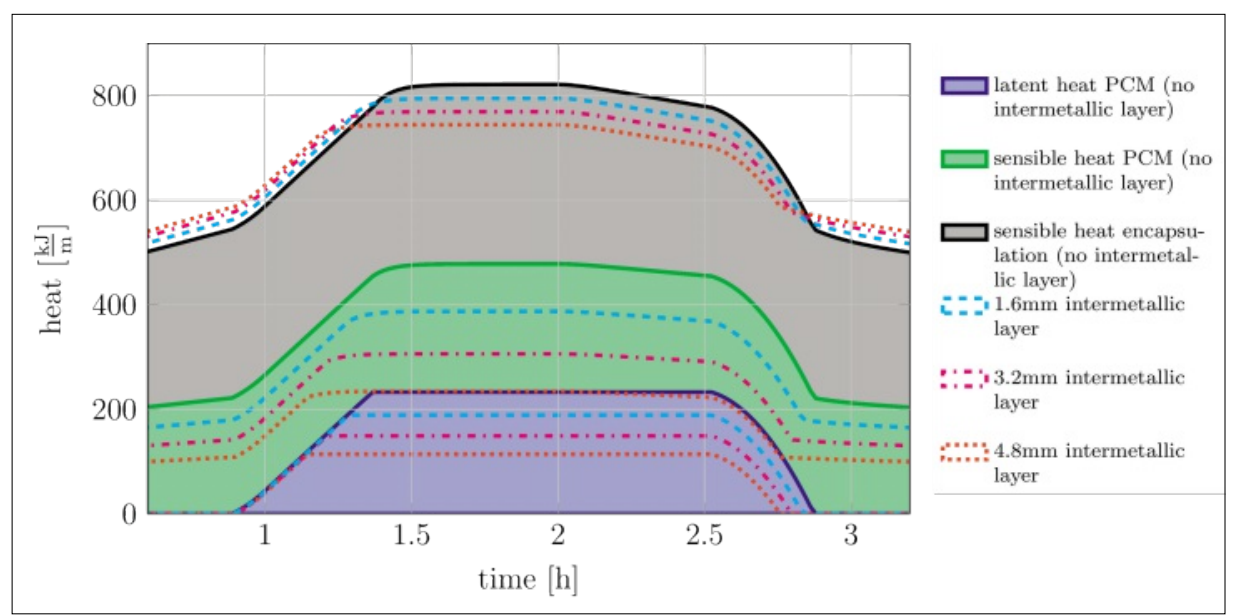

Fig. 4. Numerical prediction of the stored heat form (sensible $-h_{0}=h(T=300 \mathrm{~K})=0$ - and latent) of the AISI 316 L steel encapsulated Al-12Si during heating (charging) and cooling (discharging) initially (solid lines) and for different thicknesses of the formed Fe-Al intermetallic layer(dotted lines). same temperature boundary conditions as in Fig. 2 were used and a heat transfer coefficient of $300 \mathrm{~W} / \mathrm{m}^{2} / \mathrm{K}$ between surrounding air and cylinder was assumed. The properties of a $\mathrm{Fe}_{0.6} \mathrm{Al}_{0.4}$ interlayer were used and it was assumed that the interlayer grew symmetrically with respect to the ini-

Fig. 4 illustrates the amount of sensible and latent heat stored as the cylinder is heated (charged) and cooled (discharged). The simulation was repeated for different interlayer thicknesses to highlight the decrease in performance. As the PCM was consumed, less heat could be stored in the latent heat of the PCM. Instead more heat was stored as sensible heat in the encapsulation and interlayer. The charge and ere rates remained similar, however, the duration of melting and solidification decreased. For a heat storage system, this effectively means that a full charging cycle stores less heat and the discharge phase at constant temperature becomes shorter as 
the chemical degradation advances. Based on our model assumptions, in a material system with an interlayer of $1.6 \mathrm{~mm}$, $19 \mathrm{wt} \%$ of the PCM material was consumed and the discharging time at constant temperature was reduced by $10 \%$. The results presented in Figs 3 and 4 can be used to advance the accuracy of computational performance models of combined sensible-latent heat storage systems, such as the type described by Geissbühler et al., ${ }^{[3]}$ and models of complete AA-CAES electricity storage plants.

\section{Conclusions}

The development of tailored, encapsulated phase change material systems is crucial for the design of advanced high-temperature heat storage technologies, which are essential for enhancing the efficiency of applications such as industrial hightemperature processes, electricity storage by AA-CAES, and concentrated solar power. Our current research focuses on the challenges of finding appropriate material systems characterized by enhanced heat transfer and stable long-term performance.
We show how combined experimental and numerical methods can be used to quantify performance and degradation, and to provide design guidelines for tailored heat storage solutions guaranteeing high and stable performance over long lifetime at low costs.

\section{Acknowledgements}

This material is based upon work performed in cooperation with CTI Swiss Competence Centers for Energy Research (SCCER Heat and Electricity Storage), and with the financial support of the National Research Program 'Energy Turnaround' (NRP 70) of the Swiss National Science Foundation (SNSF) under Grant \#153780. Further information on the National Research Program can be found at www.nrp70.ch. We thank Dr. Ludger Weber and Prof. Dr. Andreas Mortensen, LMM at EPFL, for fruitful discussions.

Received: August 20, 2015

[1] Bundesamt für Energie, (BFE), 'Analyse des schweizerischen Energieverbrauchs 2000-2013 nach Verwendungszwecken', 2014.

[2] E. Power, 'The European Heat Market ECOHEATCOOL Work package 1', 2006.

[3] L. Geissbühler, S. Zavattoni, M. Barbato, G. Zanganeh, A. Haselbacher, A. Steinfeld, CHIMIA 2015, 69, 799.
[4] G. Zanganeh, R. Khanna, C. Walser, A. Pedretti, A. Haselbacher, A. Steinfeld, Sol. Energy 2015, 114, 77.

[5] B. Cárdenas, N. León, Renew. Sustain. Energy Rev. 2013, 27, 724

[6] L. Fan, J. M. Khodadadi, Renew. Sustain. Energy Rev. 2011, 15, 24

[7] O. Mesalhy, K. Lafdi, A. Elgafy, K. Bowman, Energy Convers. Manag. 2005, 46, 847.

[8] M. Liu, W: Saman, F. Bruno, Renew. Sustain. Energy Rev. 2012, 16, 2118.

[9] X. Wang, J. Liu, Y. Zhang, H. Di, Y. Jiang, Energy Convers. Manag. 2006, 47, 2211.

[10] D. Farkas, C. E. Birchenall, Metall. Trans. A 1985, 16, 323.

[11] A. F. Riechman, C. E. Birchenall, Metall. Trans. A 1980, 11, 1415.

[12] Z. Yinping, J. Yi, J. Yi, Meas. Sci. Technol. 1999, 10, 201

[13] K. Bouché, F. Barbier, A. Coulet, Mater. Sci. Eng. A 1998, 249, 167.

[14] S. Kobayashi, T. Yakou, Mater. Sci. Eng. A 2002, 338, 44.

[15] V. Voller, M. Cross, Int. J. Heat Mass Transf. 1981, 24, 545

[16] V. R. Voller, C. Prakash, Int. J. Heat Mass Transf. 1987, 30, 1709.

[17] C. A. Kherabidi, D. Groulx, CHT-15 2015, May issue.

[18] G. Pasche, M. Scheel, R. Schäublin, C. Hébert, M. Rappaz, A. Hessler-Wyser, Metall. Mater. Trans. A Phys. Metall. Mater. Sci. 2013, 44, 4119.

[19] V. N. Yeremenko, Y. V. Natanzon, V. I. Dybkov, J. Mater. Sci. 1981, 16, 1748. 